\title{
Evaluation of Carotid Vessels and Vertebral Artery in Stroke Patients with Color Doppler Ultrasound and MR Angiography
}

\author{
Dr. Pramod Shaha ${ }^{1}$, Dr. Vinay Raj $\mathbf{R}^{2}$, Dr. (Brig) K. Sahoo ${ }^{3}$
}

\begin{abstract}
Aim \& Objectives: To evaluate the cause of stroke and to compare accuracies of both Color Doppler \& MRA in stroke patients. To delineate pitfalls during imaging, interpretations and limitations of Color Doppler ultrasound. Materials \& Methods: This study was carried out in 50 patients who had presented with symptoms of strokes at Krishna institute of medical sciences, Karad from August 2013 to September 2015.Color Doppler examination and MRA was performed. Results: The highest number of stroke patients in our study were males and most common in the age group of 50 to 70 years. Hemiparesis [40\%] and family history of stroke [38 \%] were the common causes. MRA was inaccurate in assessing 50-70\% stenosis because of its false positives due to overestimation of the stenosis. Carotid Bulb was the commonest site affected by the plaque. Collaterals circulation was seen in 33 patients in MRA, none on Doppler. Conclusion: Collaterals, distal intracranial segment morphology and length of the occlusion can be better assessed by MRA. Doppler has better role in the evaluation of the morphology of the stenosis especially plaque morphology and in estimating the degree of stenosis. In cases where doppler assessment does not allow full visualization of carotid bifurcation, MRA is required.
\end{abstract}

Keywords: Color Doppler Ultrasound, Magnetic Resonance Angiography (MRA), Stroke, Carotid \& vertebral artery.

\section{Introduction}

Stroke is a syndrome characterized by the acute onset of a neurologic deficit that persist for at least 24 hours. It is 3rd most common cause of death, ischemia \& infarction constitute $85-90 \%$ while $10-15 \%$ are intracranial hemorrhage, and ICA(internal carotid artery)is responsible for about one fifth of ischemic stroke.

In most cases atherosclerosis of the large extra-cranial arteries is the underlining causes of focal cerebral ischemia, and most risk factors are hypertension, age, diabetes, cigarette smoking, and hyperlipidemia.

Atherosclerosis in the proximal ICA is most severe in the 1st $2 \mathrm{~cm}$ and two mechanisms to explain cerebral ischemia in this setting: local cerebral embolization from thrombus and reduced cerebral perfusion secondary to stenosis.

Color doppler ultrasound in stroke patients can help to detect any atherosclerotic changes or any thrombus in carotid vessels which can lead to further episodes of stroke and deterioration of patient condition. The Color Doppler evaluation of the carotid artery has been shown to be cost effective, non-invasive means of early detection of increased risk of Stroke with sensitivity approaching that of angiography.

Though it is a gold standard some calcified plaques are more delineated in doppler than MRI. Calculation of Doppler shift frequency made possible to detect the flow velocity and infarction, used to assess luminal narrowing and the degree of flow restriction, it is accurate, safe and non-invasive method of assessing arterial caliber and monitor the progression in carotid stenosis.

Then it was compared with Magnetic Resonance Angiography (MRA) which has emerged as an accurate noninvasive test to get a detailed view of carotid vessels and for evaluation of carotid stenosis.

\section{Aim and Objectives}

1) To evaluate the cause of stroke with both Color Doppler and MRA

2) To compare the accuracies of both Color Doppler and MRA in stroke patients.

3) To delineate the pitfalls during imaging, interpretations and limitations of Color Doppler ultrasound.

\section{Materials and Methods}

This study was carried out in 50 patients who came toKrishna institute of medical sciences, Karad with symptoms and signs of strokes or transient ischemic attacks, from the period of August 2013 to September 2015. A detailed clinical history was taken and clinical examination findings were recorded. Risk factors like hypertension, diabetes mellitus, cigarette smoking and ischemic heart disease were documented.

Inclusion Criteria:

- Patients coming with history of stroke.

- Patients coming for ultrasound carotid Doppler were further evaluated using MRA for plaque characterization and to determine stenosis or occlusion of carotid and vertebral artery.

\section{Exclusion Criteria:}

- Patients with any prosthetic heart valve implant, any pacemaker implant, aortic stent graft, cochlear implant,etc..

- Claustrophobic patients.

\section{Equipments used}

Color Doppler ultrasound examination of the carotid \& vertebral arteries was done using Siemens Acuson-X P500\&GE logic P5 machines with 6-12 MHz linear array probe. 


\section{International Journal of Science and Research (IJSR) \\ ISSN (Online): 2319-7064 \\ Index Copernicus Value (2013): 6.14 | Impact Factor (2015): 6.391}

MR angiography was performed on a MAGENTOM Avanto 1.5-TESLA Tim+Dot System MRI equipped with gradient overdrive with an ultrafast $120 \mathrm{mT}(\mathrm{m} \cdot \mathrm{msec})$ slow rate and high $33 \mathrm{mT} / \mathrm{m}$ peak amplitude whole-body gradient. A $4 \times 2$ circularly polarized phased array neck coil was placed around the neck. After obtaining classic fast spoiled gradient-echo axial, coronal, and sagittal localizers, 3D timeof-flight MR angiography and 3D gadolinium-enhanced MR angiography (equivocal cases) were successively performed.

\section{Results}

Study design: An observational correlation study.
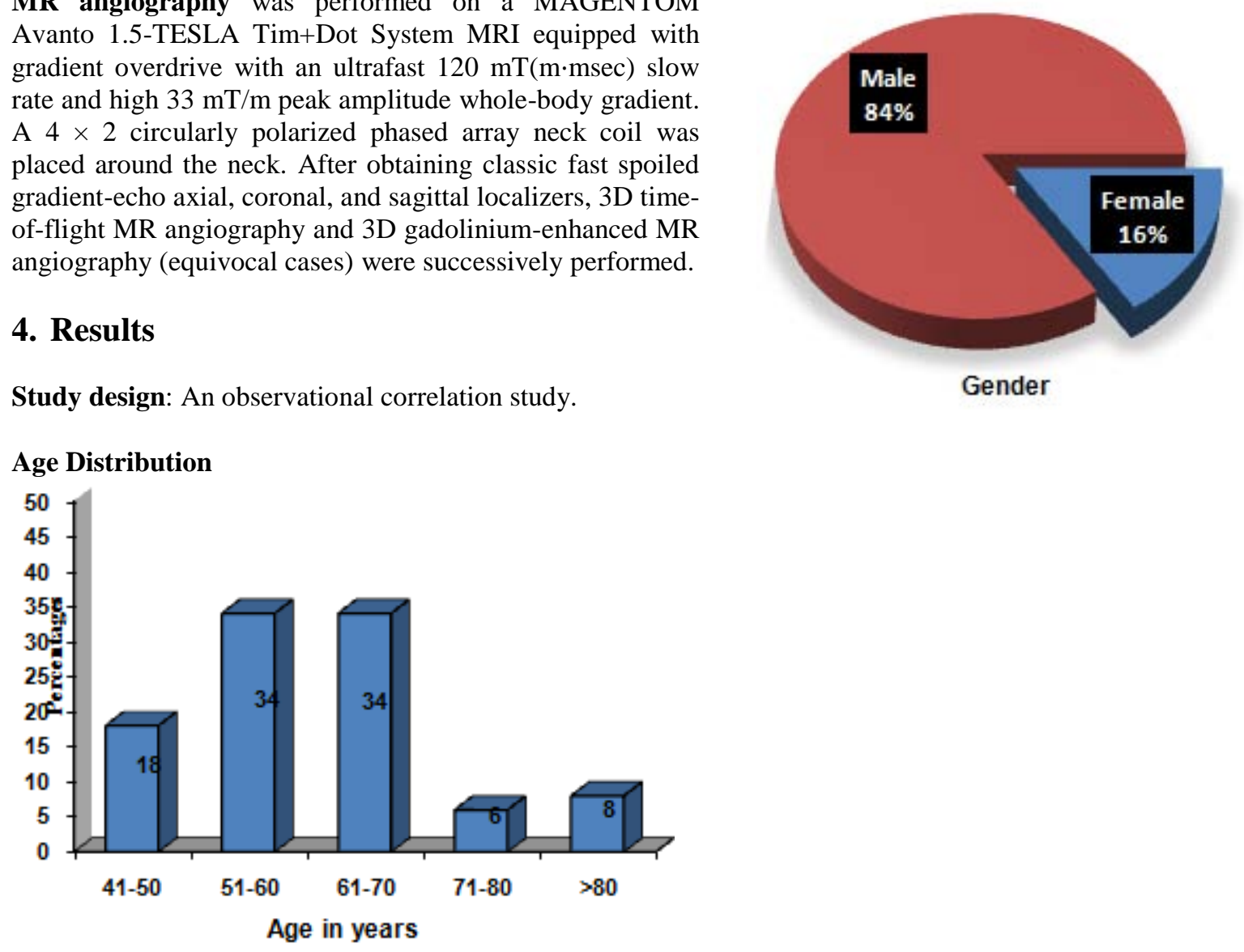

\section{Sex Distribution}

Table 1: Role of Doppler and MR Angiography in detecting Total Pathology

\begin{tabular}{|c|c|c|c|c|c|c|}
\hline TOTAL & Total & \multicolumn{2}{l|}{ DOPPLER } & \multicolumn{2}{c|}{ MRANGIOGRAPHY } & P \\
PATHOLOGIES & patients & No & $\mathbf{\%}$ & $\mathbf{N o}$ & $\mathbf{\%}$ & VALUE \\
\hline CCA & 50 & 1 & 2.0 & 1 & 2.0 & 1.000 \\
\hline BULB & 50 & 7 & 14.0 & 5 & 10.0 & $0.071+$ \\
\hline ECA & 50 & 0 & 0.0 & 0 & 0.0 & - \\
\hline ICA & 50 & 28 & 56.0 & 28 & 56.0 & 1.000 \\
\hline VERTEBRAL & 50 & 26 & 52.0 & 26 & 52.0 & 1.000 \\
\hline
\end{tabular}

Table 3: Role of Doppler and MR Angiography in 50-69\% STENOSIS

\begin{tabular}{|l|c|c|c|c|c|c|}
\hline \multirow{2}{*}{$50-69 \%$ STENOSIS } & \multirow{2}{*}{$\begin{array}{c}\text { Total } \\
\text { patients }\end{array}$} & \multicolumn{2}{|c|}{ DOPPLER } & \multicolumn{2}{|c|}{ MRANGIOGRAPHY } & \multirow{2}{*}{ P VALUE } \\
\cline { 3 - 6 } & No & $\%$ & No & $\%$ & \\
\hline CCA & 50 & 0 & 0.0 & 0 & 0.0 & - \\
\hline BULB & 50 & 2 & 4.0 & 0 & 0.0 & $0.077+$ \\
\hline ECA & 50 & 0 & 0.0 & 0 & 0.0 & - \\
\hline ICA & 50 & 1 & 2.0 & 0 & 0.0 & 0.241 \\
\hline VERTEBRAL & 50 & 0 & 0.0 & 0 & 0.0 & - \\
\hline
\end{tabular}

Table 4: Role of Doppler and MR Angiography in 70-79\% STENOSIS

\begin{tabular}{|l|c|c|c|c|c|c|}
\hline \multirow{2}{*}{$\begin{array}{c}\text { 70-79\% } \\
\text { STENOSIS }\end{array}$} & \multirow{2}{*}{$\begin{array}{c}\text { Total } \\
\text { patients }\end{array}$} & \multicolumn{2}{c|}{ DOPPLER } & \multicolumn{2}{c|}{ MRANGIOGRAPHY } & \multirow{2}{*}{ P VALUE } \\
\cline { 3 - 6 } & CCA & No & $\%$ & No & $\%$ & \\
\hline BULB & 50 & 0 & 0.0 & 0 & 0.0 & - \\
\hline ECA & 50 & 2 & 4.0 & 2 & 4.0 & 1.000 \\
\hline ICA & 50 & 0 & 0.0 & 0 & 0.0 & - \\
\hline VERTEBRAL & 50 & 1 & 2.0 & 1 & 2.0 & 1.000 \\
\hline
\end{tabular}




\section{International Journal of Science and Research (IJSR) ISSN (Online): 2319-7064 \\ Index Copernicus Value (2013): 6.14 | Impact Factor (2015): 6.391}

Table 5: Role of Doppler and MR Angiography in 80-99\% STENOSIS

\begin{tabular}{|l|c|c|c|c|c|c|}
\hline \multirow{2}{*}{ 80-99\% STENOSIS } & Total patients & \multicolumn{2}{|c|}{ DOPPLER } & \multicolumn{2}{c|}{ MRANGIOGRAPHY } & \multirow{2}{*}{ P VALUE } \\
\cline { 3 - 6 } & & No & $\%$ & No & $\%$ & \\
\hline CCA & 50 & 0 & 0.0 & 0 & 0.0 & - \\
\hline BULB & 50 & 0 & 0.0 & 2 & 4.0 & $0.077+$ \\
\hline ECA & 50 & 0 & 0.0 & 0 & 0.0 & - \\
\hline ICA & 50 & 0 & 0.0 & 1 & 2.0 & 0.241 \\
\hline VERTEBRAL & 50 & 0 & 0.0 & 0 & 0.0 & - \\
\hline
\end{tabular}

Table 6: Role of Doppler and MR Angiography in Complete Occlusion

\begin{tabular}{|c|c|c|c|c|c|c|}
\hline \multirow{2}{*}{$\begin{array}{c}\text { Complete } \\
\text { Occlusion }\end{array}$} & Total patients & \multicolumn{2}{|c|}{ DOPPLER } & \multicolumn{2}{|c|}{ MRANGIOGRAPHY } & P VALUE \\
\cline { 2 - 6 } & & No & $\%$ & No & $\%$ & \\
\hline CCA & 50 & 1 & 2.0 & 1 & 2.0 & 1.000 \\
\hline BULB & 50 & 0 & 0.0 & 0 & 0.0 & - \\
\hline ECA & 50 & 0 & 0.0 & 0 & 0.0 & - \\
\hline ICA & 50 & 26 & 52.0 & 26 & 52.0 & 1.000 \\
\hline VERTEBRAL & 50 & 26 & 52.0 & 26 & 52.0 & 1.000 \\
\hline
\end{tabular}

+ Suggestive significance (P value: $0.05<\mathrm{P}<0.10$ )

* Moderately significant ( $\mathrm{P}$ value:0.01<P $\leq 0.05$ )

** Strongly significant (P value: $\mathrm{P} \leq 0.01$ )

\section{Discussion}

\section{Age and Sex Distribution}

Palomaki $\mathrm{H}$ et al studied the risk factors for cervical atherosclerosis in patients with ischemic stroke and transient ischemic attack and found that incidence of stroke increases after 60 years of age. ${ }^{1}$

The highest number of stroke patients in our study were found in the age group of 51- 60 and 61-70 years which was $34 \%$ that is 17 patients in $51-60$ years and 17 patients in 6170 years followed by 41-50 years which was 18\% [9 patients] , > 80years is $8 \%$ [ 4 patients] and $71-80 \%$ is $6 \%$ [3 patients].

Lemolo $\mathrm{F}$ et al. in his study showed that only $2.5 \%$ of stroke victims were females. In this study $84 \%$ of the patients (42/50) were males and $16 \%$ [8/50] of the patients were females. $^{2}$

\section{Clinical History}

Schulz U. G. R. Flossmann E and Rothwell studied family history of stroke and found that $23 \%$ of stroke patients had positive family history of stroke. ${ }^{3}$

In this study family history of stroke was present in 19 patients [38\%].Hemiparesis was seen in 20 patients [40\%] and family history of stroke in 19 patients [38\%] were the main presenting complaints and symptoms.

\section{Role of Doppler and MR Angiography in Stenosis}

Grading of the stenosis was done according to the North American Symptomatic Carotid Endarterctomy Trial (NASCET) criteria. In comparison of the Doppler and MRA findings in the evaluation of the total pathologies. Doppler showed abnormalities in the Bulb in 7 patients [14\%] whereas in MRA it is 5 patients [10\%].

Erickson S.J et al (1989) analyzed 49 patients with various Doppler velocity parameters for carotid artery stenosis and correlated with angiography. They found that B-mode measurement of diameter stenosis is most accurate at less than $40 \%$ diameter stenosis. In our study, the comparison of the Doppler and MRA findings in evaluation of $16-49 \%$ stenosis. Doppler showed abnormalities in the Bulb in 3 patients [6\%] whereas in MRA it is 1 patient [2\%].

J.M.Serfaty et al found that MRA is inaccurate in assessing $50-70 \%$ stenosis because of its false positives due to overestimation of the stenosis. ${ }^{4}$ In our study, comparison of the Doppler and MRA findings in evaluation of the $50-69 \%$ stenosis. Doppler showed abnormalities in 3 patients [6\%] whereas in MRA it is 0 . The difference was found to be stastically significant.

Paul J.Nederkoorn, Yolanda vander graff, M.G.Myriam Hunink found that MRA has better discriminatory power compared with duplex ultrasonography in detecting 70-99\% stenosis. For detecting occlusion both MRA and ultrasound are accurate. $^{5}$

In our study comparison of the Doppler and MRA findings in evaluation of the $70-79 \%$ stenosis. Abnormal findings are equal on both doppler and MRA.

In $80-99 \%$ stenosis. MRA showed abnormalities in 3 patients [6\%] whereas in the Doppler it is 0. The difference was found to be statistically significant. In evaluation of complete occlusion. Abnormal findings are equal on both doppler and MRA which is similar to the experience of Paul.J.Nederkoorn as stated above.

\section{Morphology of Stenosis}

Doppler showed abnormalities in 9 patients whereas in MRA it is 6 . The difference was found to be statistically significant. This difference is MR Angiography is because of its relative insensitivity to arterial calcification. In evaluation of the collaterals. Abnormal findings were seen in 33 patients in MRA, none on Doppler.

\section{Common Site of Stenosis}

Zwiebel $\mathrm{J}$ found that the carotid bifurcation was commonly involved by the atherosclerotic plaque followed by the origin of carotid. In our study also Bulb was found to be the commonest site affected by the plaque. 


\section{International Journal of Science and Research (IJSR) \\ ISSN (Online): 2319-7064}

Index Copernicus Value (2013): 6.14 | Impact Factor (2015): 6.391

\section{Conclusion}

1) MRA has been developed as an alternative technique to digital subtraction angiography in the evaluation of intracranial and extracranial vasculature as it is noninvasive and gives a more precise estimate of stenosis because it provides a direct measurement of stenotic lumen.

2) MRA has better discriminatory power compared with duplex ultrasonography in detecting $80-99 \%$ stenosis. For detecting occlusion, both MRA and ultrasound are accurate.

3) Doppler has better role in the evaluation of the morphology of the stenosis especially plaque morphology and in estimating the degree of stenosis.

4) Collaterals, distal intracranial segment morphology and length of the occlusion can be better assessed by MRA and this method is not operator dependent.

5) In cases where doppler assessment does not allow full visualization of carotid bifurcation, MRA is required.

\section{Images of Cases}

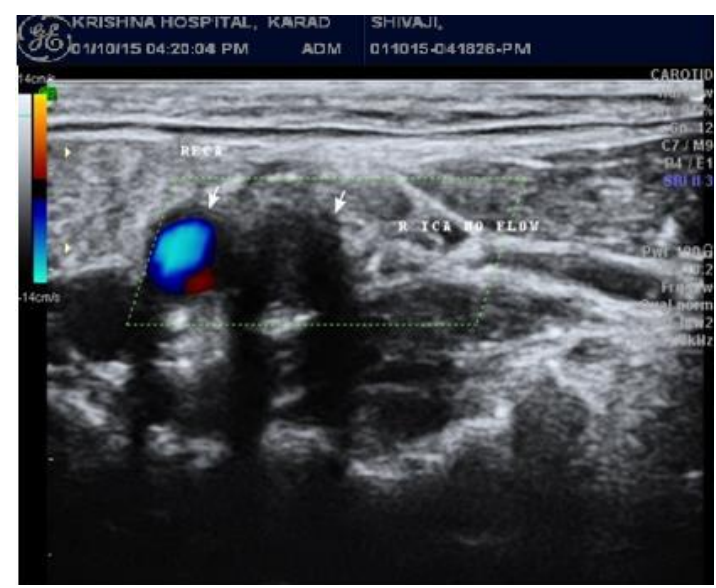

Figure 1: Transverse US image withthrombus in Right ICA showing No Flow on Colour Doppler

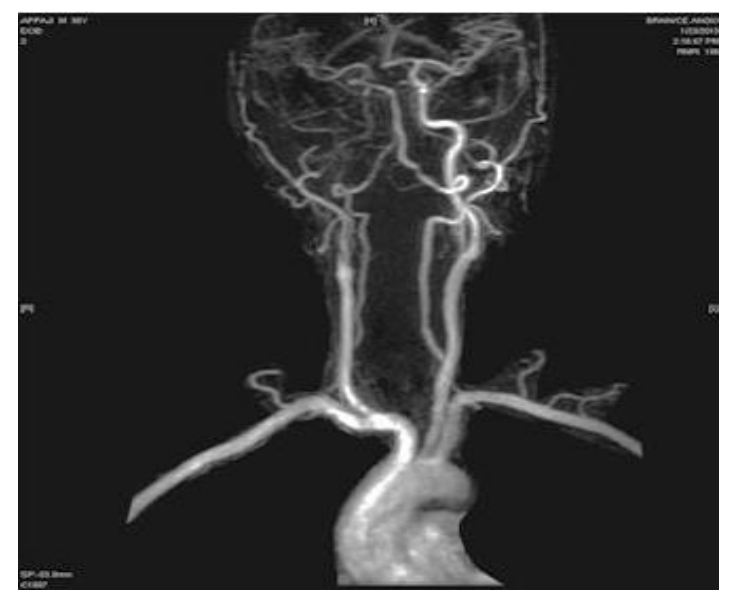

Figure 2: Complete occlusion of Right ICA on MRA
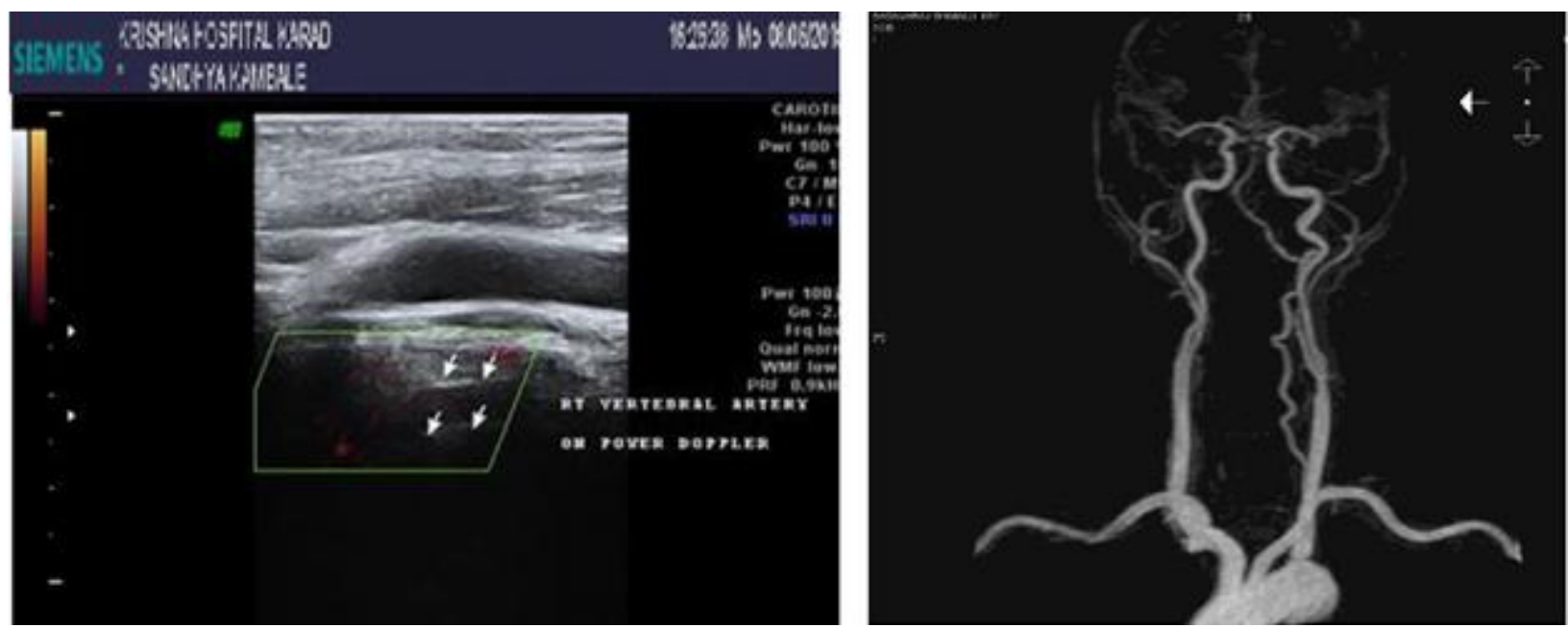

Figure 3 \& 4: Right Vertebral Artery Showing No Flow on Power Doppler and MRA 


\section{International Journal of Science and Research (IJSR) \\ ISSN (Online): 2319-7064 \\ Index Copernicus Value (2013): 6.14 | Impact Factor (2015): 6.391}

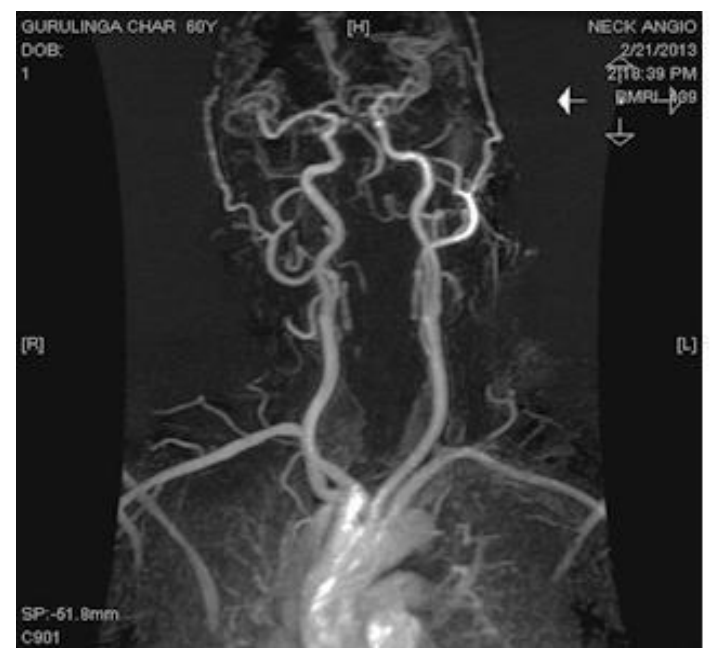

Figure 5: Complete occlusion of bilateral vertebral arteries on MRA

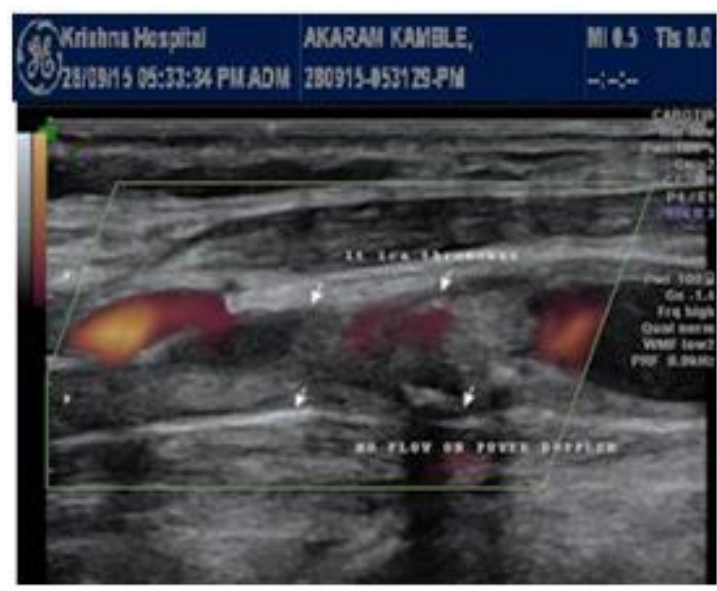

Figure 6: Left ICA thrombus showing no flow on power doppler

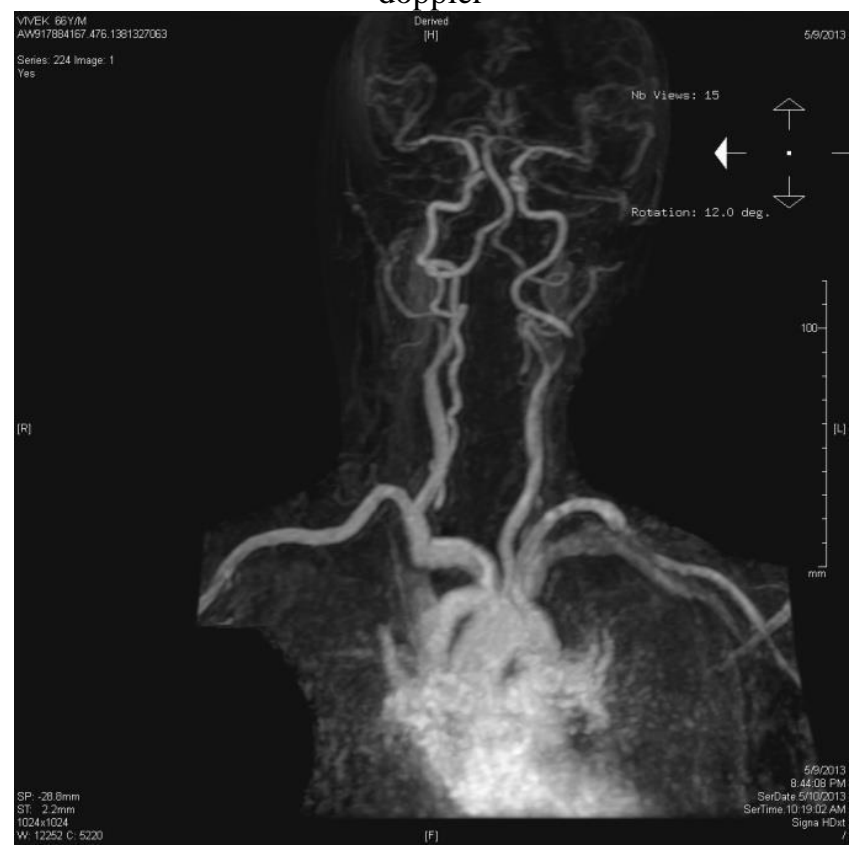

Figure 7: MRA showing occlusion of bilateral vertebral arteries at its origin from subclavian artery but reformatted by collaterals distally

\section{References}

[1] Palomaki H, Kaste M, Raininko R et al: „Risk factors for cervical atherosclerosis in patients with transient ischemic attack or minor ischemic stroke": Stroke 1993;24:970-975.

[2] Lemolo F, Martiniuk A, Dteinman DA, Spence JD: "Sex differences in carotid plaque and stenosis" : Stroke 2004. Feb; 35(2): 477-81.

[3] Schulz UGR, Flossmann E, Rothwell P: "Heritabilty of ischemic stroke to age. vascular risk factors. and subtypes of incident stroke in population based studies": Stroke 2004 Apr ;35(4): 819-824

[4] J.M.Serfaty , P. Chirossel, J.M.Chevallier et al :Accuracy of three dimensional gadolinium enhanced MR angiography in the assessment of the extracranial carotid artery disease: AJR2000;175 :455-463.

[5] Paul .J.Nederkoorn,Yolanda vander graff, M.G.Myriam Hunink : Duplex Ultrasound and Magnetic Resonance Angiography Compared With Digital Subtraction Angiography in Carotid Artery Stenosis: A Systematic Review :Stroke 2003 ; 34 :1324-1332.

[6] Aburahma Au F, wuIu John T, Crotty Brad: "Carotid plaque ultrasonic heterogeneity and severity of Stenosis": Stroke 2002; 33:1772.

[7] Zweibel william J: "Doppler evaluation of carotid stenosis" chapter 10 Introduction to vascular ultrasonography .4th edition W.B. Saunders company 2000; 146-151.

[8] Caroli BA. Carotid Ultrasound. Neuroimaging clinics of North America.1996: 6:875-897.

[9] Nederkoorn PJ, Mali WP, Eikelboom BC, et al: Duplex Ultrasound and magnetic resonance angiography are sensitive for severe carotid stenosisll: The Journal of Family Practice 2002 Nov; 51, No. 11.

[10]Hwang CS, Liano KM, Lee J.H, Tegeler CH: -Measurement of carotid stenosis: comparsions between duplex and different angiographic grading methods\|Journal of Neuroimaging. 2003 Apr; 13(2)133-139. 